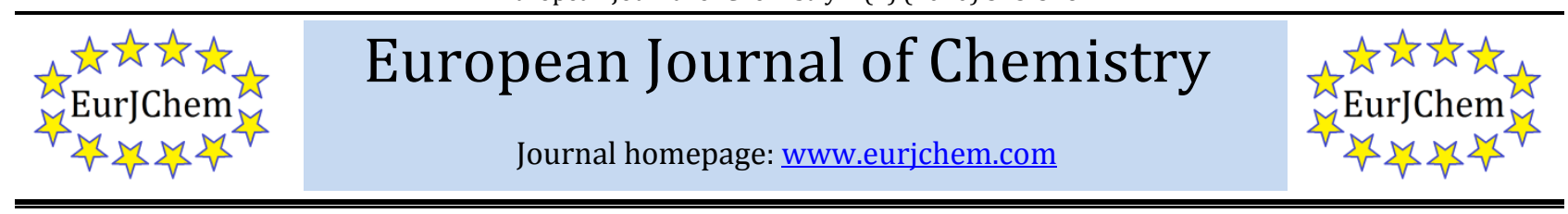

\title{
Stabilization of 5-aminolevulinic acid by the zinc(II) ion in an aqueous solution
}

\author{
Hiroshi Sakiyamaa,*, Hidetatsu Inouea, Md.Kudrat-E-Zahana, Shoichi Huekib, \\ Naohisa Tachiya ${ }^{b}$ and Yuzo Nishida ${ }^{a}$ \\ a Department of Material and Biological Chemistry, Faculty of Science, Yamagata University, Kojirakawa, Yamagata, JP-990-8560, Japan \\ b Cosmo Oil Co., Ltd., Shibaura, Minatoku, Tokyo, JP-105-8528, Japan
}

${ }^{*}$ Corresponding author at: Department of Material and Biological Chemistry, Faculty of Science, Yamagata University, Kojirakawa, Yamagata, JP-990-8560, Japan Tel.: +81.23.6284601; fax: +81.23.6284591. E-mail address: saki@sci.kj.yamagata-u.ac.jp (H. Sakiyama).

\section{COMMUNICATION INFORMATION}

Received: 06 May 2010

Received in revised form: 09 June 2010

Accepted: 22 June 2010

Online: 31 December 2010

\section{KEYWORDS}

\section{5-aminolevulinic acid}

Zinc(II) ion

UV-VIS absorption spectra

NMR

$\mathrm{pH}$

\section{Introduction}

5-Aminolevulinic acid (5-ALA) (Scheme 1) is the precursor of all tetrapyrroles in biological systems [1]; in the case of mammals, heme is synthesized from 5-ALA, and, in the case of green plants, chlorophyll is synthesized from 5-ALA. In both biosynthetic processes, two 5-ALA molecules are condensed to give porphobilinogen by an enzyme, 5 -aminolevulinic acid dehydratase (EC 4.2.1.24); however, without the enzyme, two 5-ALA molecules are condensed in a different manner to give different products [2-6]. The mechanism of this autocondensation of 5-ALA was studied by Jaffe and coworkers [2] and Novo and coworkers [3]. They reported that two 5-ALA molecules were condensed to form 2,5-bis(2-carboxyethyl) dihydropyrazine(2,5-dihydropyrazinedipropionic acid, HPDPA) and then HPDPA was oxidized by molecular oxygen to form 2,5-bis(2-carboxyethyl)pyrazine(2,5-pyrazinedipropionic acid, PDPA).<smiles>CCCCCC(=O)CCC(=O)O</smiles>

Scheme 1

Recently 5-ALA has been used as a fertilizer for tomatoes, wine grapes, strawberries, and other crops; however, the autocondensation of 5-ALA reduces the concentration of 5-ALA in the fertilizer solution, which is a problem. Therefore, we are looking for a method to stabilize 5-ALA in an aqueous solution of neutral $\mathrm{pH}$. In the auto-condensation, the first condensation process is thought to start with a nucleophilic attack by a lone pair of the amino group of 5-ALA to a $\gamma$-carbonyl carbon of another 5-ALA molecule. Therefore, if metal ions are added to a 5-ALA solution and bind to the amino groups of 5-ALA molecules, the initial nucleophilic attack will be stopped, and 5-ALA molecules should be stabilized. In this study, we examined the effect of a zinc(II) ion because the zinc(II) ion is colorless and diamagnetic due to its $d^{10}$ electronic configuration and is suitable for UV-Vis Spectroscopy and NMR Spectroscopy.

\section{Experimental}

\subsection{Measurements}

Electronic spectra were recorded on a Jasco V-560 spectrometer. ${ }^{1} \mathrm{H}$ and ${ }^{13} \mathrm{C}$ NMR spectra $(400 \mathrm{MHz})$ were recorded on a JEOL JNM- $\alpha 400$ spectrometer in $\mathrm{D}_{2} \mathrm{O}$ using sodium 3-trimethylsilyl-2,2,3,3-tetradeuteropropionate (TSP) as the internal standard.

\subsection{Materials}

Hydrochloric salt of 5-ALA (5-ALA $\cdot \mathrm{HCl})$ was prepared by Cosmo Oil Co., Ltd. using a fermentation method [7]. All other chemicals were commercial products and were used as supplied.

\section{Results and discussion}

\subsection{Auto-condensation reaction of 5-ALA monitored by electronic spectra}

Before examining the stabilization effect of zinc(II) ion, the auto-condensation reaction of 5-ALA was monitored by the 

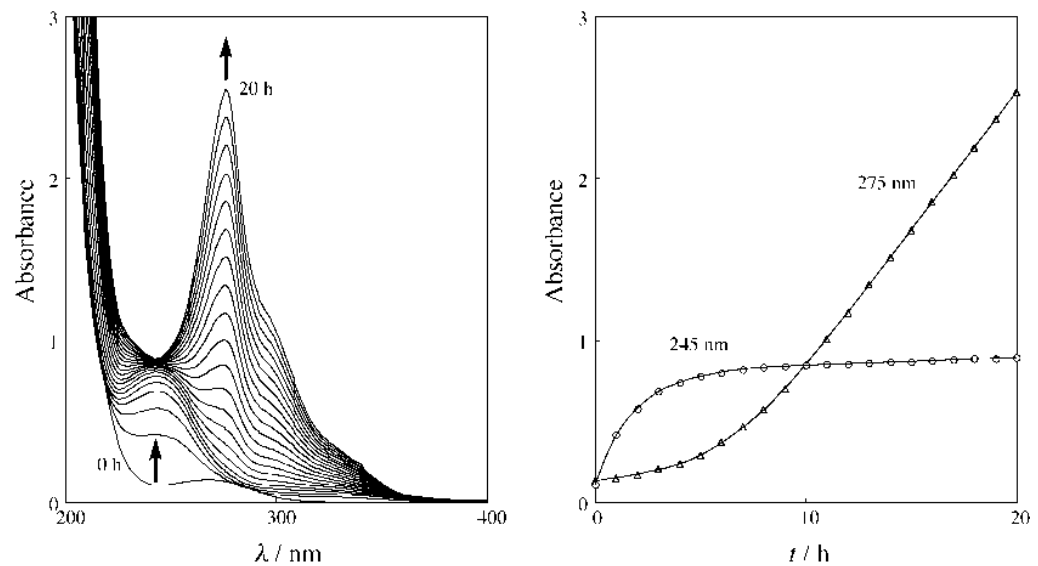

Figure 1. Electronic spectral change for an aqueous 5-ALA solution (left) and time dependencies of the absorbance for the solution at $245 \mathrm{~nm}(0)$ and $275 \mathrm{~nm}(\Delta)$ (right). Conditions: 5 -ALA $\cdot \mathrm{HCl}(20$ $\mu \mathrm{mol})$ and $\mathrm{LiOH}(40 \mu \mathrm{mol})$ in $5 \mathrm{~mL}$ of water under aerobic conditions at room temperature $(\mathrm{pH}=8.0)$. Measurements were conducted for 20 hours at one-hour intervals.
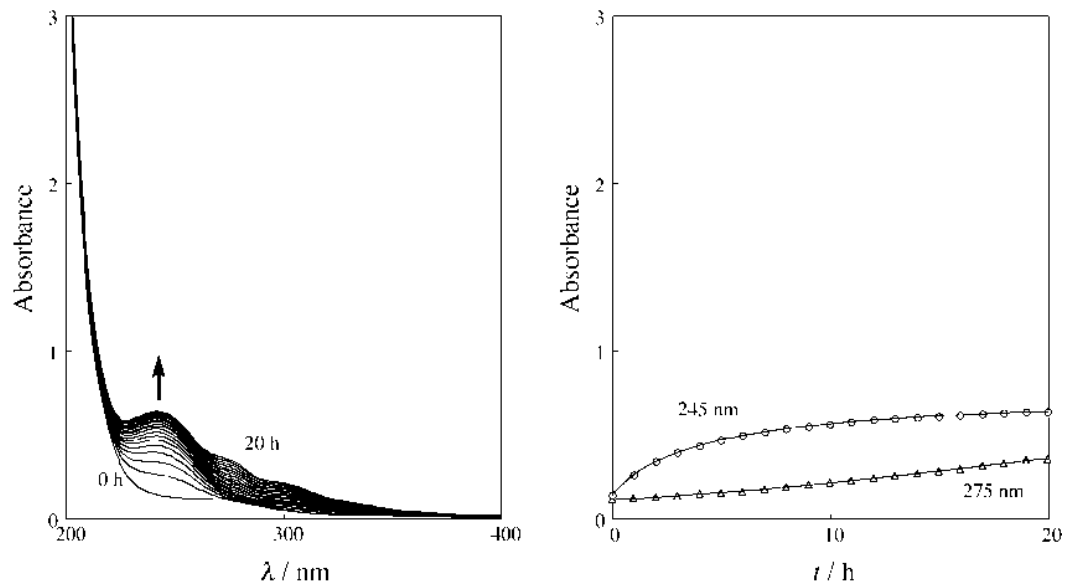

Figure 2. Electronic spectral change for an $\mathrm{N}_{2}$-exchangerd aqueous 5-ALA solution (left) and time dependencies of the absorbance for the solution at $245 \mathrm{~nm}(\mathrm{O})$ and $275 \mathrm{~nm}(\Delta)$ (right). Conditions: 5 -ALA $\cdot \mathrm{HCl}(20 \mu \mathrm{mol}), \mathrm{LiOH}(40 \mu \mathrm{mol})$ in $5 \mathrm{~mL}$ of water under $\mathrm{N}_{2}$ condition at room temperature. Measured for 20 hours at one hour intervals.

electronic spectra as follows. An aqueous solution of 5-ALA $(\mathrm{pH}=\sim 8)$ was prepared by mixing $5-\mathrm{ALA} \cdot \mathrm{HCl}$ and lithium hydroxide (LiOH) in a 1:2 molar ratio, and the absorption spectra of the resulting solution were measured for 20 hours at one-hour intervals (Figure 1). At first, a new absorption band appeared at around $245 \mathrm{~nm}$, and then another band appeared at around $275 \mathrm{~nm}$ together with two shoulder bands at around $300 \mathrm{~nm}$ and $330 \mathrm{~nm}$. The result is consistent with the results of Novo and coworkers [3]; the appearance of the first band at around $245 \mathrm{~nm}$ corresponds to the formation of HPDPA, and the second band at around $275 \mathrm{~nm}$ corresponds to the formation of PDPA. An experiment was also carried out under nitrogen (Figure 2), and as anticipated, the first band appeared at around $245 \mathrm{~nm}$ as well as in the aerobic experiment; however, the intensity of the second band at around $275 \mathrm{~nm}$ was significantly smaller than that in the aerobic experiment.

\subsection{Stabilization of 5-ALA by zinc(II) ion}

The effect of zinc(II) ion on the auto-condensation of 5-ALA was examined by the method described in Section 3.1. In the presence of $\mathrm{ZnCl}_{2}$ in the molar ratio of 5-ALA: $\mathrm{ZnCl}_{2}$ (2:1), the rate of PDPA formation decrease to about 15\% (Figure 3) [slope of absorbance at $275 \mathrm{~nm}: 2.5 \times 10^{-2} \mathrm{~min}^{-1}$ in Figure 3 and $1.7 \times 10^{-1} \mathrm{~min}^{-1}$ in Figure 1]. It is noteworthy that the subtle precipitation of zinc hydroxide caused an increase in the absorbance in a wide wave-length range just after preparing the solution, but this disappeared within several hours. When $\mathrm{ZnCl}_{2}$ was added to a 5-ALA solution in a 1: 1 molar ratio, the rate of PDPA formation became less than $5 \%$ (Figure 4) [slope of absorbance at $275 \mathrm{~nm}: 7.1 \times 10^{-3} \mathrm{~min}^{-1}$ in Figure 4]. The formation of HPDPA and PDPA was significantly inhibited by the zinc(II) ion, and we can conclude that the zinc(II) ion stabilizes 5-ALA in solution.

The stabilization effect of the zinc(II) ion was also ascertained by ${ }^{1} \mathrm{H}$ and ${ }^{13} \mathrm{C}$ NMR (Figure 5 and 6). Without the zinc(II) ions, the signals of 5-ALA [ ${ }^{1} \mathrm{H}$ NMR: $\delta=2.71(\mathrm{t}, 2 \mathrm{H})$; $2.90(\mathrm{t}, 2 \mathrm{H}) ; 4.13(\mathrm{~s}, 2 \mathrm{H}) \mathrm{ppm} ;{ }^{13} \mathrm{C}$ NMR: $\delta=30.4 ; 37.3 ; 50.0$; 179.8; $207.0 \mathrm{ppm}]$ disappeared, and the signals of HPDPA $\left[{ }^{1} \mathrm{H}\right.$ NMR: $\delta=2.40(\mathrm{~s}, 2 \mathrm{H}) ; 2.42(\mathrm{t}, 2 \mathrm{H}) ; 2.57(\mathrm{t}, 2 \mathrm{H}) \mathrm{ppm} ;{ }^{13} \mathrm{C}$ NMR: $\delta$ $=36.2 ; 36.2 ; 36.3 ; 175.8 ; 184.5 \mathrm{ppm}]$ appeared; however, with zinc(II) ions (5-ALA:ZnCl, 1:1), the signals of 5-ALA remained, and a small amount of HPDPA was observed [ ${ }^{1} \mathrm{H}$ NMR: $\delta=2.51$ $(\mathrm{t}, 2 \mathrm{H}) ; 2.81(\mathrm{t}, 2 \mathrm{H}) ; 4.09(\mathrm{~s}, \sim 1.1 \mathrm{H}) \mathrm{ppm} ;{ }^{13} \mathrm{C}$ NMR: $\delta=33.5$; 36.08 (HPDPA); 38.8; 50.2; 183.9; $208.9 \mathrm{ppm}$ ]. In the ${ }^{1} \mathrm{H}$ NMR in the presence of zinc(II) ions (Figure 5c), the integrated intensity of the $\delta$-methylene protons was smaller than expected; this may be explained by the $\mathrm{D}-\mathrm{H}$ exchange through enolization of 5-ALA in $\mathrm{D}_{2} \mathrm{O}$ [2]. In the presence of zinc(II) ions, the ${ }^{1} \mathrm{H}$ NMR signals shifted downfield as compared with the solution without zinc(II) ions at $\mathrm{pH} 7(\delta=2.45 ; 2.75 ; 4.05 \mathrm{ppm})$ [2]; this may suggest the coordination of 5-ALA to the zinc(II) ion to form a zinc(II) complex. 

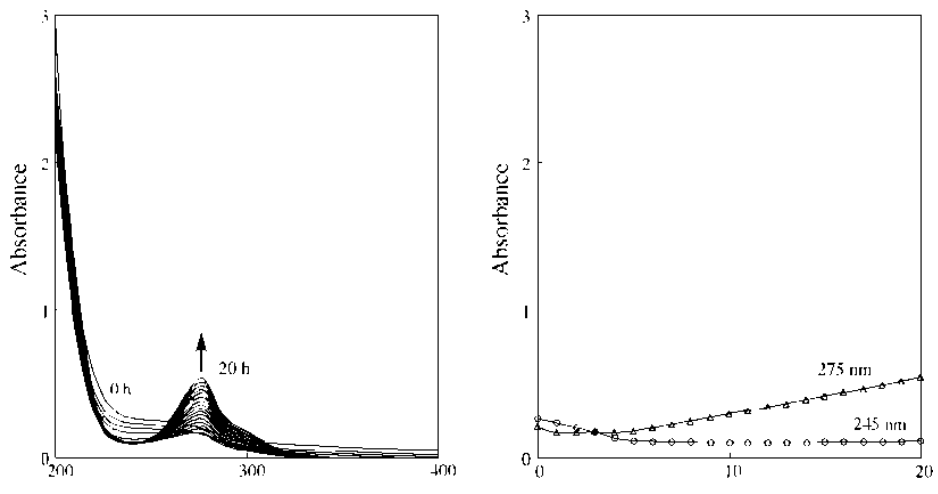

Figure 3. Electronic spectral change for an aqueous 5-ALA solution in the presence of zinc(II) ion (left) and time dependencies of the absorbance for the solution at $245 \mathrm{~nm}(\mathrm{O})$ and $275 \mathrm{~nm}(\Delta)$ (right). Conditions: 5-ALA $\cdot \mathrm{HCl}(20 \mu \mathrm{mol}), \mathrm{ZnCl}_{2}(10 \mu \mathrm{mol})$, and $\mathrm{LiOH}(40 \mu \mathrm{mol})$ in $5 \mathrm{~mL}$ of water under aerobic conditions at room temperature $(\mathrm{pH}=7.2)$. Measurements were conducted for 20 hours at one-hour intervals.
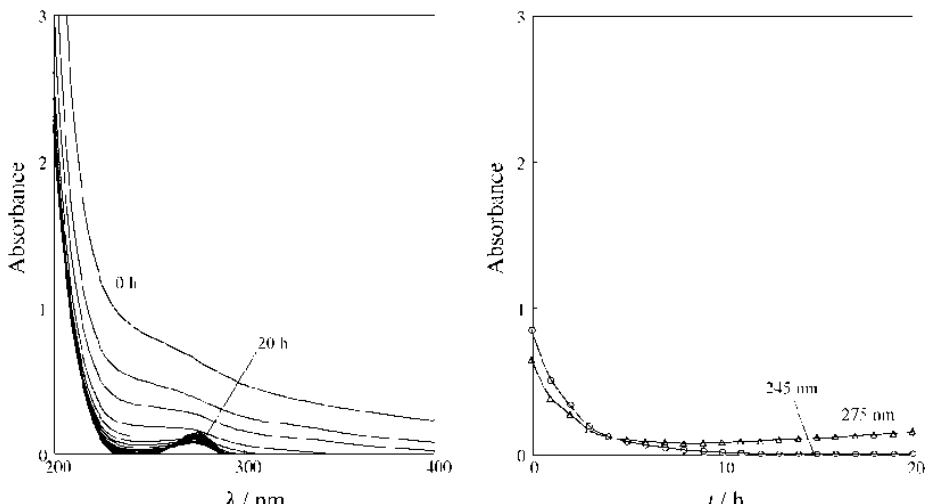

Figure 4. Electronic spectral change for an aqueous 5-ALA solution in the presence of zinc(II) ion (left) and time dependencies of the absorbance for the solution at $245 \mathrm{~nm} \mathrm{(o)} \mathrm{and} 275 \mathrm{~nm}(\Delta)$ (right). Conditions: 5-ALA $\cdot \mathrm{HCl}(20 \mu \mathrm{mol}), \mathrm{ZnCl}_{2}(20 \mu \mathrm{mol})$, and $\mathrm{LiOH}(40 \mu \mathrm{mol})$ in $5 \mathrm{~mL}$ of water under aerobic conditions at room temperature $(\mathrm{pH}=6.7)$. Measurements were conducted for 20 hours at one-hour intervals.

a

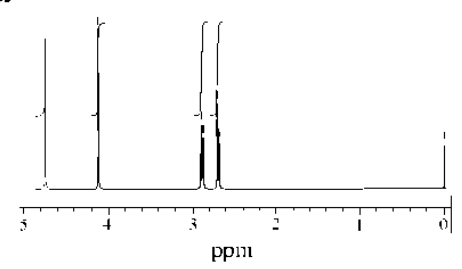

b

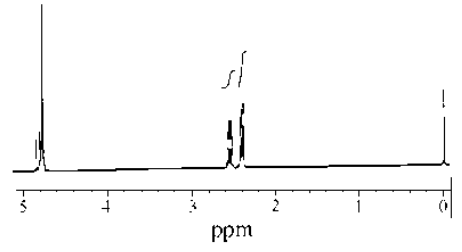

$\mathrm{c}$

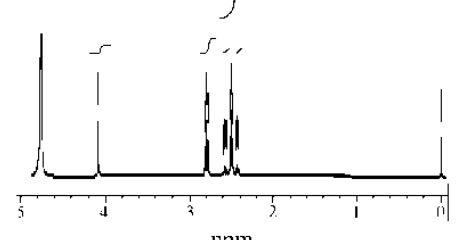

ppm

Figure 5. ${ }^{1} \mathrm{H}$ NMR spectra of 5-ALA in $\mathrm{D}_{2} \mathrm{O}$ : (a) 5-ALA $\cdot \mathrm{HCl}$, (b) neutralized with $\mathrm{LiOH}$, and (c) neutralized with $\mathrm{LiOH}$ in the presence of $\mathrm{ZnCl}_{2}(\mathrm{pH}=7)$ a

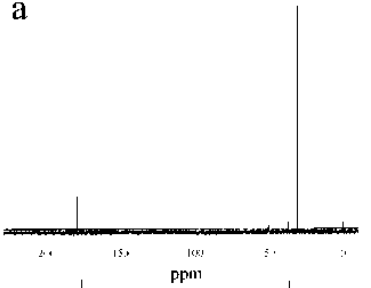

b

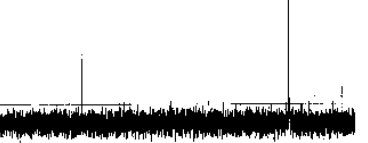

ppin

c

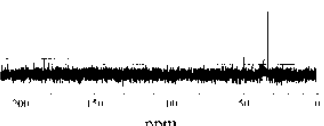

Ppit

Figure $6 .{ }^{13} \mathrm{C}$ NMR spectra of 5-ALA in $\mathrm{D}_{2} \mathrm{O}$ : (a) 5-ALA $\mathrm{HCl}$, (b) neutralized with $\mathrm{LiOH}$, and (c) neutralized with $\mathrm{LiOH}$ in the presence of $\mathrm{ZnCl}_{2}(\mathrm{pH}=7)$. 


\subsection{Stabilization mechanism of 5-ALA by zinc(II) ion}

As reported in the introduction, the auto-condensation of 5-ALA starts with a nucleophilic attack by a lone pair of the amino group of 5-ALA to a $\gamma$-carbonyl carbon of another 5-ALA molecule. Judging from the downfield shift in ${ }^{1} \mathrm{H}$ NMR, 5-ALA seems to coordinate to the zinc(II) ion to form a zinc(II) complex. Since the lone pair is used for the coordination bond in the complex, the initial nucleophilic attack cannot occur, and 5-ALA molecules are stabilized. Although the zinc(II) complex has not been isolated, attempts to do so is underway.

\section{Conclusion}

A method of stabilizing 5-ALA at neutral $\mathrm{pH}$ was being required in order to use 5-ALA for some application purposes. It is known that 5-ALA is not stable in an aqueous solution at neutral $\mathrm{pH}$. In this study, the zinc(II) ion was found to stabilize 5-ALA in an aqueous solution of neutral $\mathrm{pH}$ by forming a zinc(II) complex.

\section{References}

[1]. Shemin, D.; Russell, C. S. J. Am. Chem. Soc. 1953, 75, 4873-4874.

[2]. Jaffe, E. K.; Rajagopalan, J. S. Bioinorg. Chem. 1990, 18, 381-394.

[3]. Novo, M.; Hüttmann, G.; Diddens, H. J. Photochem. Photobiol. B. Biol. 1996, 34, 143-148.

[4]. Elfsson, B.; Wallin, I.; Eksborg, S.; Rudaeus, K.; Ros, A. M.; Ehrsson, H. Eur. J. Pharm. Sci. 1998, 7, 87-91.

[5]. Bunke, A.; Zerbe, O.; Schmid, H.; Burmeister, G.; Merkle, H. P.; Gander, B. J. Pharm. Sci. 2000, 89, 1335-1341.

[6]. Gadmar, Ø. B.; Moan, J.; Scheie, E.; Ma, L. W.; Peng, Q. J. Photochem. Photobiol. B: Biol. 2002, 67, 187-193.

[7]. Nishikawa, S.; Watanabe, K.; Tanaka, T.; Miyachi, N.; Hotta, Y.; Murooka, Y. J. Biosci. Bioeng. 1999, 87, 798-804. 